ISSN 1112-9867

\title{
ASSESSING STUDENTS'ABILITIES IN INTERPRETING THE CORRELATION AND REGRESSION ANALYSIS
}

\author{
F. A. Razak, N. Baharun, N. A. Deraman and N. R. P Ismail* \\ Faculty of Computer and Mathematical Sciences, UniversitiTeknologi MARA,35600Tapah, \\ Perak, Malaysia
}

Published online: 17 October 2017

\begin{abstract}
A case study was carried out on students who were being exposed to some theoretical concepts of the correlation and regression topics to investigate their ability to compute and interpret the Pearson's correlation coefficient and the slope of regression. The findings revealed that a low percentage of students (19.43\%) successfully completed their interpretation of correlation coefficient and $33.18 \%$ of the students managed to interpret the computed value of regression slope completely. It was also found that the students' ability to interpret regression slope was significantly associated with the ability to interpret the correlation coefficient correctly. It is hoped that the findings obtained from this study will shed some light on improving teaching practices of statistics educators so as to help students in gaining better understanding on interpreting the correlation and regression analysis.
\end{abstract}

Keywords: correlation; Pearson; regression; coefficients; interpretation; students' ability.

Author Correspondence, e-mail: norra914@perak.uitm.edu.my

doi: http://dx.doi.org/10.4314/jfas.v9i5s.45 


\section{INTRODUCTION}

Statistical literacy is an important skill in todays' technological societies. Statistics is widely applied in science, economics, engineering, social sciences, health, sports and many more. Specifically, at UniversitiTeknologi MARA (UiTM), statistics is one of the subjects taught in several diploma programs such as Computer Sciences, Accountancy, Applied Sciences, Estate Management, Quantity Survey, Architecture and Plantation and Agro technology. Statistics is also offered in UiTM as part of a major study, starting from undergraduate to postgraduate programs. For a specific program majoring in statistics, one of the program outcomes is to produce a competent statistician who can apply statistical thinking in decision making and solving real life problems. According to[1], the goal of statistics education is to facilitate statistical thinking whereby students should emerge from statistics classes with an appreciation for when and how the application of statistics in their professional or personal lives is warranted and with a willingness to think statistically (or probabilistically) in relevant situations. Indeed,“....statistics in particular, data are not just a matter of numbers; statistics deal with numbers as well as providing a "context" making problems more realistic and forcing students and teachers to think about the validity and applicability of their solutions" $[2]$.

Fundamentals of Regression Analysis course (STA250) is a compulsory subject that must be taken by students in order to fulfil the requirement for the Diploma in Statistics at UiTM. Besides, this subject is also taken by students in Diploma in Actuarial Sciences (compulsory subject) and Diploma in Mathematics (elective subject). In learning this subject, it has been observed that students tend to focus more on calculation part and ignore the writing part where they need to make conclusions and interpretations based on the calculations. Even when they do write, the statistical statements are often incomplete, incorrect or imprecise. These are observed many times in students work, be it assignments, quizzes, tests or final examination. The written words require deep understanding of the topic and not just memorizing the notes given by the lecturer. When students are weak in understanding the concept in regression analysis, coupled with English language problem, they fail to write correct statistical statements which are so important in research report.

The ability to interpret is one of the critical components in statistical literacy. Students who 
are taking statistics course should be able not only to calculate the value of a sample statistic but most importantly able to interpret the statistical information. Moreover, with the development of scientific calculators and statistical software packages like Minitab and SPSS, anyone can obtain the statistic value without doing or knowing the tedious calculation steps involved. Statistics students should be equipped with all the statistical literacy skills required to function effectively as needed by the industry. To cope with the requirements of the industry, in [3] suggests some changes in statistical education such as less emphasis on measure theory and probability theory and greater emphasis on visual analyses and interpretation coupled with data analysis.

This study was based on exploratory study which aimed to investigate student's ability to write proper interpretation of the values calculated in correlation and regression analysis. In specific, the objectives were set as follows:

i. To investigate student's ability to write the interpretation based on the value calculated in correlation and regression analysis.

ii. To compare the difference of scores between students who can write the interpretation in correlation analysis properly and students who cannot.

iii. To compare the difference of scores between students who can write the interpretation in regression analysis properly and students who cannot.

iv. To investigate the association between students' ability to interpret correlation coefficient and the ability to interpret the regression slope.

\section{LITERATURE REVIEW}

According to [4], the term "statistical literacy" is used to emphasize that the purpose of the school curriculum should not be only to produce statisticians but also to prepare statistically literate school graduates who are well equipped to participate in social decision making. Students who leave school must not only be able to do statistical tests, but more importantly they should be able to interpret statistical information themselves. Aligned with [5], statistical literacy is defined as the ability to interpret, critically evaluate and communicate statistical information and messages. It is asserted that statistically literate behavior is grounded on the joint activation of five interrelated knowledge bases (literacy, statistical, mathematical, 
context and critical) together with a cluster of supporting dispositions and enabling beliefs. A study was conducted in [6] which aimed to investigate the competence level in statistics among secondary school students' in Brunei and revealed that the level of statistics literacy among them is low with the mean percentage test score of $35.5 \%$.

Furthermore, it was identified in [7] that completing a course in statistics does not inevitably lead to statistical insight. Many students learn statistics as a set of rules without always learning the meaningful context in which they should be applied. Students should be able to relate a task to an appropriate schema or model and does not blindly apply rules. Additionally, the study in [7] showed that assessment approaches that focus only on computational aspects of statistics may lead to students' poor understanding of statistical concepts. In learning statistics, students should be trained with questions that require explanation and interpretation of the statistics either from the value that they had computed or from the statistical output obtained [8]. Statistical expertise typically involves more than mastering facts and calculations, therefore, the assessment should capture students' ability to reason, communicate and apply their statistical knowledge [9].

There was a study carried out in [10] which examined the student's errors and difficulties in understanding elementary statistical concepts. If association between two quantitative variables exist, a function $y=f(x)$ (regression line) will be constructed using the least squares approach to predict the value of $y$ from the value of $\mathrm{x}$. The student's understanding of the chosen criterion would allow him to correctly interpret the line of regression and the relation of the line with the data (goodness of fit). Even when the line of regression has been determined, it is still possible to commit errors in its interpretation or when making prediction such as performing illegal extrapolation.

According to [11], many of the problems with students learning statistics stem from too many concepts having to be operationalized almost simultaneously. Mastering and interlinking many concepts is too much for most students to cope with. The difficulty of students to interpret statistical analysis is believed to be caused by their negative boldness towards statistics [12-13] and problems with basic English expression [14]. For instance, in [14] highlighted the difficulty of students to see the difference of the following two statements: "There is a slight tendency for older people to watch less television (correlation is weak)" and 
“Older people tend to watch slightly less television (regression coefficient is small)".A study by [15] which is conducted among foreign students studying in Australia found that the weaknesses in English will create learning difficulties and therefore reduce the confidence level in taking a proactive role in classrooms.

\section{VARIABLES DEVELOPMENT}

In this study, the main interest is the students' responses to Question 1a and Question 2a (see Table 1). The variables developed in this study were constructed from these two questions. The first variable developed was based on the interpretation of the Pearson's correlation coefficient,r (Question 1a), while the second variable of interest was grounded on the interpretation on the slope of regression, $b_{1}$ (Question 2a).

Table 1. Items used for variables development

\begin{tabular}{l} 
No Question \\
\hline $1 \quad$ A research was conducted to investigate the relationship between waist size \\
and body fat percentage among females with ages between $30-40$ years old. \\
A random sample of 10 females in a certain town area was selected and data \\
on the waist size (in cm) and body fat (in percent) was obtained. \\
a) Find the Pearson's coefficient of correlation. What does the value mean? \\
The number of pounds of steam used per month at a plant is thought to be \\
related to the average monthly ambient temperature. The past year's usages \\
and temperatures recorded for 12 months was obtained. \\
a) Fit a simple linear regression equation for the data given and explain the \\
slope value.
\end{tabular}

\subsection{Pearson's (Product Moment) Correlation Coefficient}

The Pearson's (Product Moment) Correlation Coefficient is a numerical value that measures the strength and direction of a linear relationship between two quantitative variables, $\mathrm{X}$ and $\mathrm{Y}$. The symbol used for the correlation coefficient calculated from any sample is $r$ and it has a value that ranges from -1.0 to +1.0 . The Pearson's correlation coefficient can be calculated using the formula, scientific calculator or any statistical software like SPSS, Excel or Minitab. 
Usually, students can calculate $\mathrm{r}$ correctly but the problem arises when they are asked to interpret the value.

Hence, in this study, investigation on the ability of students to interpret the value of Pearson's correlation coefficient, $r$ was performed. From the question (see Table 1), the most appropriate interpretation can be suggested as: "The value of $r=0.876$ indicates that there is a strong positive linear relationship between waist size and body fat."While students are free to interpret their calculated $\mathrm{r}$ in any manner they like, their interpretation should however convey all the important points. In this interpretation for instance, students are advised to mention on the strength (either strong, moderate or weak), direction (positive linear or negative linear) and the two variables involved (in this case, they were waist size and body fat). Using these guidelines, students' ability to interpret $r$ are divided into three main categories:

i. Complete interpretation of $\mathbf{r}$ (An interpretation stating all the important information in any way that can be clearly understood)

ii. Incomplete interpretation of $\mathbf{r}$ (An interpretation that can be understood but with one or more important information missing from the statement).

iii. Wrong or no interpretation of $\mathbf{r}$ (An interpretation that is completely incorrect or some calculation with no interpretation provided).

\subsection{Slope of the Fitted Regression Equation}

The relationship between a dependent variable $\mathrm{Y}$ and an independent variable $\mathrm{X}$ is postulated as a linear model:Y $=\beta_{0}+\beta_{1} X+\varepsilon$,where $\beta_{0}$ and $\beta_{1}$ are unknown constants called the model regression coefficients or parameters. $\mathrm{Y}$ is a dependent variable whose values we wish to predict or estimate while $\mathrm{X}$ is an independent variable that provides the basis for estimation. The coefficient $\beta_{\mathrm{o}}$ is the mean value of $\mathrm{Y}$ when $\mathrm{X}=0$. On the other hand, $\beta_{1}$ is the slope of the regression and may be interpreted as the change in the mean of $\mathrm{Y}$ produced by a unit change in $\mathrm{X}$. The parameters $\beta_{0}$ and $\beta_{1}$ are usually unknown and must be estimated. Therefore, the model of $Y=\beta_{0}+\beta_{1} X+\varepsilon$ will be represented by the fitted equation, $Y($ hat $)=b_{0}+b_{1} X$ [16].From the fitted equation, the second variable of interest to be studied is the ability of students to interpret the value of slope, $b_{1}$. The estimated slope, $\left(b_{1}\right)$ from Question $2 a$ is 9.2085. This value can be interpreted as "The value 9.2085 indicates that for every $1{ }^{\circ} \mathrm{C}$ increase in the mean temperature, the amount of steam used per month would increase by 
9.2085 pounds". Students may also explain this value as "The average amount of steam used per month would increase by 9.2085 pounds for each $1^{\circ} \mathrm{C}$ increment of the mean temperature". Using any way of interpretation, students need to identify the unit $\left(1^{\circ} \mathrm{C}\right)$ of increment of the independent variable (mean temperature) and the amount (9.2085) effect (increase or decrease) to the dependent variable (amount of steam used per month).

Guided by this, students' ability to interpret $b_{1}$ were divided into three categories:

i. Complete interpretation of $b_{1}$ (An interpretation stating all the important information in any way that can be clearly understood).

ii. Incomplete interpretation of $b_{1}$ (An interpretation that can be understood but with one or more important information missing from the statement).

iii. Wrong or no interpretation of $b_{1}$ (An interpretation that is completely incorrect or some calculation with no interpretation provided).

\subsection{Conceptual Framework}

In Figure 1, the conceptual framework of this study is presented. It supports the specific objectives of this research which is to identify the association between ability to write the interpretation of $r$ (correlation analysis) and ability to write the interpretation of $b_{1}$ (regression analysis). Included in the framework are the total score for Question 1 and the total score for Question 2, which is meant to inspect whether the ability to interpret the statistics ( $r$ and $b_{1}$ ) will affect the total score obtained. This conceptual framework leads authors through the steps of selecting an appropriate analysis, reflecting on the results and writing a report.

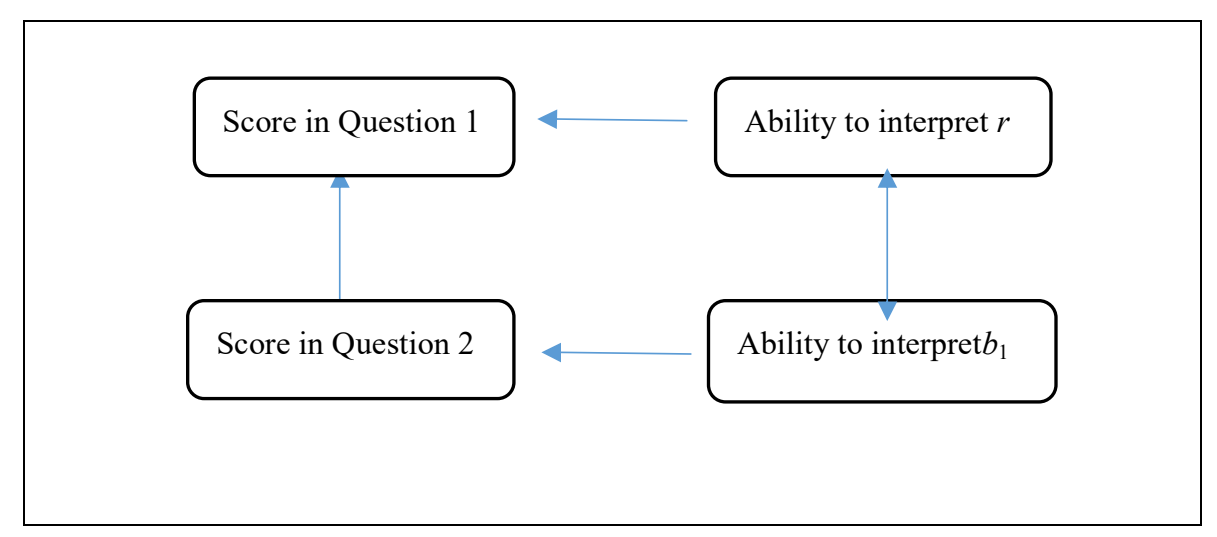

Fig.1.Conceptual framework 


\section{METHODOLOGY}

The target population for this study is all diploma students $(\mathrm{N}=211)$ registered for the STA250 course in UiTM Perak Branch, Tapah Campus during December 2016-April 2017 session. The students were mainly from Diploma in Statistics (CS111) and Diploma in Actuarial Sciences (CS112).Both programs scheduled STA250 course to be registered in semester 4, however there were some students who signed up for this course in higher semester ( 5,6 or 7$)$. These students either joined this course for the second or third time (repeating the course) or have been delayed in their enrolment for some valid reasons.

The students were given a common test after seven weeks of lectures to measure their understanding in correlation analysis (Question 1:10 marks), regression analysis (Question 2:20 marks) and model adequacy checking (Question 3:10 marks). All the answer scripts were graded guided by an answer scheme as is the usual practice. However, for this study each answer script was studied again to identify the categories of interpretation for both correlation coefficient and slope value (Question 1a and 2a). Total marks using the answer scheme for both Question 1 and Question 2 obtained by each student were also recorded. The data was then analyzed using IBM SPSS Statistics 23.

Additionally, it is important to state here that, this study only focused on the ability to interpret the correlation coefficient and slope of regression in the context of the problem. Therefore, if the students gave precise explanation from their wrong computed values, it is still considered as complete. Similarly, if students were unable to compute anything (blank answers), the response is categorized as no interpretation even though they had not attempted to interpret as there was no values to be interpreted.

\section{RESULTS AND DISCUSSION}

Table 2 summarizes some demographic information of the respondents. Out of 211 students, female respondents comprise $72.5 \%$ of the population while the remaining $27.5 \%$ are males. $52.1 \%$ of the students registered in Diploma in Statistics and $47.9 \%$ registered in Diploma in Actuarial Sciences. 
Table 2.Demographic information of respondent $(\mathrm{N}=211)$

\begin{tabular}{cc}
\hline Variable & Frequency (\%) \\
\hline Gender & $58(27.5 \%)$ \\
Male & $153(72.5 \%)$ \\
Female & \\
Program & $110(52.1 \%)$ \\
Diploma in Statistics & 101 \\
Part 4 & 8 \\
Part 5 & 0 \\
Part 6 & 1 \\
Part 7 & $101(47.9 \%)$ \\
Piploma in Actuarial Science & 97 \\
Part 4 & 1 \\
Part 5 & 3 \\
Part 6 & \\
\hline
\end{tabular}

The first objective of the study is to investigate the student's ability to write the interpretation based on the value calculated in the correlation and regression analysis.

Table 3. Performance of students in Question 1a

\begin{tabular}{cccc}
\hline Ability to Interpret the Value of $\mathbf{r}$ & Frequency (\%) & Mean & SD \\
\hline Complete interpretation & $41(19.43 \%)$ & 9.4 & 1.1 \\
Incomplete interpretation & $131(62.09 \%)$ & 9.1 & 1.0 \\
Wrong or no interpretation & $39(18.48 \%)$ & 7.3 & 2.0 \\
Total & $\mathbf{2 1 1}(\mathbf{1 0 0 \% )}$ & & \\
\hline
\end{tabular}

Only $19.43 \%$ of the students successfully gave complete interpretation of $r$ (see Table 3 ). Most of the students (62.09\%) attempted to interpret but with incomplete information while $18.48 \%$ either did not give any interpretation or provide inappropriate explanation. The mean scores in Question 1 were high (9.4 and 9.1 respectively) with low variation ( $\mathrm{SD}=1.1$ and $\mathrm{SD}=1.0$ respectively) for those who gave complete and incomplete interpretation of $\mathrm{r}$ and only 7.3 for those who gave wrong or no interpretation. Some of students' interpretation that were 
considered as incomplete or wrong were listed in Table 4 (These samples were taken exactly as the answer they had provided using their computed statistics).Generally, most of the students overlooked either the strength, direction or the variables involved in giving their explanation, with some only mentioned "Strong relationship" as their explanation. A number of them mistakenly interpreted $\mathrm{r}$ as the coefficient of determination, $\mathrm{R}^{2}$ or the slope.

Table 4. Examples of incomplete and wrong interpretation of correlation coefficient

\begin{tabular}{cc}
\hline No Students' Responses on Coefficient of & Comment \\
Correlation, $r$ &
\end{tabular}

1 Strong relationship.

2 There is strong linear relationship between waist size and body fat.

3 There is positive linear relationship The strength of the relationship was between waist size $(\mathrm{cm})$ and body fat. not mentioned.

4 The Pearson's coefficient of correlation is 0.87596. It shows that it has strong and positive relationship.

5 The value of $\mathrm{r}$ is 0.8760 and it is a strong correlation.

6 The value mean is strong positive correlation.

7 The value explains that there is a strong coefficient of correlation.

8 Strong positive Pearson's coefficient correlation.

9 If the waist size is increased $1 \mathrm{~cm}$, the body fat will increase 0.87606 .

$1087.596 \%$ of waist size can be explained by Totally wrong interpretation. percentage of body fat.

From Table 5, we found that $33.18 \%$ of the students managed to interpret the computed value of $b_{1}$ completely with the mean score of 18 out of 20 . Most of the students (51.65\%) either 
gave wrong interpretation or did not challenge to give any, with average marks of 14.5. In comparison to Question 1, even though the percentage of ability to give complete interpretation was higher for Question 2a, though the variation of the total score is also greater for each of different abilities ( $\mathrm{SD}=3.1$ to $\mathrm{SD}=4.6$ ). The examples of responses that were considered as incomplete or wrong is listed in Table 6. Again, these were taken exactly as the answer they had provided using their own statistics value obtained. General flaws observed among the responses are ignoring the variables involved and the amount of change, failure to assign the independent and dependent variable correctly, and slight understanding on the definition of slope.

Table 5. Performance of students in Question 2a

\begin{tabular}{cccc}
\hline Ability to Interpret the Value of $\mathbf{b}_{\mathbf{1}}$ & Frequency (\%) & Mean & SD \\
\hline Complete interpretation & $70(33.18 \%)$ & 18.0 & 3.1 \\
Incomplete interpretation & $32(15.17 \%)$ & 17.8 & 3.3 \\
Wrong or no interpretation & $109(51.65 \%)$ & 14.5 & 4.6 \\
Total & $211(100 \%)$ & & \\
\hline
\end{tabular}

Table 6. Examples of incomplete and wrong interpretation of regression slope

\begin{tabular}{|c|c|c|}
\hline No & $\begin{array}{l}\text { Students' Responses on Slope of the } \\
\text { Regression Equation, } b_{1}\end{array}$ & Comment \\
\hline 1 & $\begin{array}{l}\text { The change of mean of the temperature is } \\
\text { increases by } 0.10858105 \text { produced by } \\
\text { increases of } 1000 \text { unit of usage. }\end{array}$ & $\begin{array}{l}\text { Independent and dependent variables } \\
\text { were assigned wrongly from the } \\
\text { beginning. }\end{array}$ \\
\hline 2 & $\begin{array}{l}\text { If temperature decreases by } 1^{\circ} \mathrm{C} \text {, the number } \\
\text { of ponds of steam used will increases by } \\
\text { approximately } 920.85 \text { pound. }\end{array}$ & $\begin{array}{l}\text { Unable to grasp the idea of positive } \\
\text { slope. }\end{array}$ \\
\hline 3 & $\begin{array}{l}\text { If the average monthly ambient temperature } \\
\text { increase by } 1{ }^{\circ} \mathrm{C} \text {, the number of pounds of } \\
\text { steam used per month at a plant increases by } \\
\text { approximately } 9208.50 \text {. }\end{array}$ & $\begin{array}{l}\text { The dependent variable given as } \\
\text { "usage/1000" was misinterpreted. }\end{array}$ \\
\hline
\end{tabular}


4 The slope will increasing, y-intercept is Unable to interpret the value -24219.7 and the gradient is 57.5218 . obtained.

5 For every increase of 1 unit in $\mathrm{X}, \mathrm{Y}$ also increase.

6 The slope value show that the increase in value of $\mathrm{x}$ will affect the increase of

General comment without referring to the situation given. predicted value of $y$.

7 Increase in temperature, the average usage The amount of increment in the will increase by 9.2085 . independent variable was not mentioned.

8 The temperature increase 9208.46 by usage. Unable to grasp the idea of the effect

9 Increase in 1000 in usage will increase of independent variable to the temperature by 9.21 in ambient temperature. dependent variable.

Further analysis was done to compare the difference scores in Question 1 between students who interpret $\mathrm{r}$ completely and students who cannot. Similarly, the difference of scores in Question 2 is tested between students who can write the interpretation of $b_{1}$ completely and students who cannot. A non-parametric test was used since the normality assumption and homogeneity of variances between groups were not met. The Kolmogorov Smirnov statistics for Question 1 and Question 2 score are $\mathrm{D}=0.216(\mathrm{p}$-value $=0.000)$ and $\mathrm{D}=0.151$ (p-value $=0.000)$ respectively. The Levene's test for Question 1 score was $14.168(\mathrm{df1}=2, \mathrm{df} 2=208)$ with the p-value $<0.01$. This indicated that the variance of score for each ability in interpreting $\mathrm{r}$ were not equal. Similarly, for Question 2 score between the different ability in interpreting $b_{1}$, the Levene's test was $13.182(\mathrm{df} 1=2, \mathrm{df} 2=208)$ with the $\mathrm{p}$-value $<0.01$. This also indicated that the variance score in Question 2 were not equal among the three different abilities.

The Kruskal-Wallis test was carried out to determine the difference in Question 1 score among the three different abilities to interpret $r$. The result (see Table 7) shows a statistically significant difference in Question 1 score across three different categories $(1, n=41$ : students who can write the complete interpretation, 2, $\mathrm{n}=131$ : students who gave incomplete interpretation, 3 , $n=39$ : students who made wrong or no interpretation of $r), \chi^{2}(2, N=211)=$ 
$48.25, \mathrm{p}<0.001$.

Advance analysis was performed to investigate which group was significantly differ from the others. For that purpose, a Mann Whitney test was performed for each pair of categories (Complete and incomplete, complete and wrong, incomplete and wrong). To control for Type-I error, a Bonferroni adjustment was applied to the alpha values by dividing the alpha level of 0.05 with the number of pairs (Bonferroni adjustment $=0.05 / 3=0.0167$ ).

A Mann-Whitney test (see Table 8) revealed no significant difference in Question 1 score of students who can interpret the value of $\mathrm{r}$ completely $(\mathrm{Md}=10, \mathrm{n}=41)$ and students who gave incomplete interpretation $(\mathrm{Md}=9.5, \mathrm{n}=131), \mathrm{z}=-2,194, \mathrm{p}=0.028$. However, there was a significant difference in Question 1 score of students who can interpret the value of $r$ completely $(\mathrm{Md}=10, \mathrm{n}=41)$ and students who cannot interpret or wrongly interpret the value of $\mathrm{r}(\mathrm{Md}=7.5, \mathrm{n}=39), \mathrm{z}=-5.853, \mathrm{p}<0.001$. Moreover, there was also a significant difference in Question 1 score of students who can interpret the value of $\mathrm{r}$ but incompletely $(\mathrm{Md}=9.5$, $\mathrm{n}=131)$ and students who cannotinterpret or wrongly interpret the value of $r(\mathrm{Md}=7.5, \mathrm{n}=39)$, $\mathrm{z}=-6.158, \mathrm{p}<0.001$. The median score for Question 1 was higher for students who gave incomplete interpretation on the value of $\mathrm{r}$ compared to students who cannotinterpret or wrongly interpret the value of $\mathrm{r}$ (see Table 7).

Table 7. Median score for Question 1 and 2 according to three categories of interpretation abilities $(\mathrm{N}=211)$

\begin{tabular}{lcccc}
\hline \multicolumn{1}{c}{ Variable } & $\mathbf{n}$ & $\mathbf{M d}^{\mathbf{a}}$ & $\chi^{2} \mathbf{s t a t}^{\mathbf{b}}(\mathbf{d f})$ & $\mathbf{p}-$ Value \\
\hline Ability to interpret the value of $\mathrm{r}$ & & & & \\
1. Complete interpretation & 41 & 10.0 & & \\
2. Incomplete interpretation & 131 & 9.5 & $48.25(2)$ & $0.000^{*}$ \\
3. Wrong or no interpretation & 39 & 7.5 & & \\
Ability to interpret the value of $\mathrm{b}_{1}$ & & & & \\
1. Complete interpretation & 70 & 18.0 & $37.92(2)$ & $0.000^{*}$ \\
2. Incomplete interpretation & 32 & 17.8 & & \\
3. Wrong or no interpretation & 109 & 14.5 & & \\
\hline
\end{tabular}

${ }^{\mathrm{a}} \mathrm{Md}=$ Median; ${ }^{\mathrm{b}}$ Kruskal-Wallis test; ${ }^{*}$ The median difference is significant at the $\mathrm{p}<0.001$

In the analysis of Question 2 scores, the Kruskal-Wallis test (see Table 7) discovered a 
statistically significant difference in Question 2 score across three different categories (1, $\mathrm{n}=70$ : students who can write the complete interpretation, 2, $\mathrm{n}=32$ : students who gave incomplete interpretation, $3, n=109$ : students who made wrong or no interpretation of $b_{1}$ ), $\chi^{2}(2, N=211)=37.92, p<0.001$. Further analysis of Mann Whitney test (see Table 8) revealed no significant difference in Question 2 score of students who can interpret the value of $b_{1}$ completely $(M d=18, n=70)$, and students who interpreted the value of $b_{1}$ incompletely $(\mathrm{Md}=17.8, \mathrm{n}=32), \mathrm{z}=-0.494, \mathrm{p}=0.621$. However, a significant difference observed in Question 2 score of students who can interpret the value of $b_{1}$ completely $(M d=18, n=70)$ and students who cannot interpret or wrongly interpret the value of $b_{1}(M d=14.5, n=109)$, $\mathrm{z}=-5.510, \mathrm{p}<0.001)$. Furthermore, there is a significant difference in Question 2 score of students who interpreted the value of $\mathrm{b}_{1}$ incompletely $(\mathrm{Md}=17.8, \mathrm{n}=32)$ and students who cannot interpret or wrongly interpret the value of $b_{1}(\mathrm{Md}=14.5, \mathrm{n}=109), \mathrm{z}=-4.250, \mathrm{p}<0.001$.

Table 8. Multiple comparison on the median score for Question 1 and 2 among three different abilities in interpreting $\mathrm{r}$ and $\mathrm{b}_{1}(\mathrm{~N}=211)$

\begin{tabular}{|c|c|c|c|c|c|c|}
\hline & Variable & $\begin{array}{l}\text { Comparison Between } \\
\text { Categories of Ability }\end{array}$ & $\mathbf{n}$ & $\mathbf{M d}^{\mathbf{a}}$ & Z-stat ${ }^{b}$ & p-Value \\
\hline \multirow{6}{*}{ 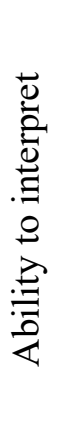 } & \multirow{6}{*}{ 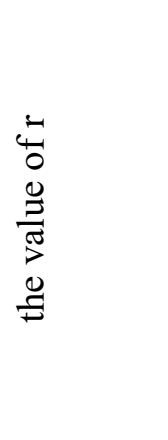 } & 1. Complete interpretation & 41 & 10.0 & \multirow{2}{*}{-2.194} & \multirow{2}{*}{0.028} \\
\hline & & 2. Incomplete interpretation & 131 & 9.5 & & \\
\hline & & 1. Complete interpretation & 41 & 10 & \multirow{2}{*}{-5.853} & \multirow{2}{*}{$0.000^{*}$} \\
\hline & & 3.Wrong or no interpretation & 39 & 7.5 & & \\
\hline & & 2.Incomplete interpretation & 131 & 9.5 & \multirow{2}{*}{-6.158} & \multirow{2}{*}{$0.000^{*}$} \\
\hline & & 3. Wrong or no interpretation & 39 & 7.5 & & \\
\hline \multirow{6}{*}{ 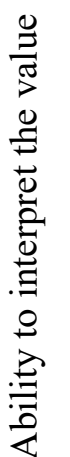 } & \multirow{6}{*}{$\frac{\overrightarrow{0}}{4}$} & 1. Complete interpretation & 70 & 18.0 & \multirow{2}{*}{-0.494} & \multirow{2}{*}{0.621} \\
\hline & & 2. Incomplete interpretation & 32 & 17.8 & & \\
\hline & & 1. Complete interpretation & 70 & 18.0 & \multirow{2}{*}{-5.510} & \multirow{2}{*}{$0.000^{*}$} \\
\hline & & 3. Wrong or no interpretation & 109 & 14.5 & & \\
\hline & & 2. Incomplete interpretation & 32 & 17.8 & \multirow{2}{*}{-4.250} & \multirow{2}{*}{$0.000^{*}$} \\
\hline & & 3. Wrong or no interpretation & 109 & 14.5 & & \\
\hline
\end{tabular}

${ }^{\mathrm{a}} \mathrm{Md}=$ Median; ${ }^{\mathrm{b}}$ Mann-Whitney test; ${ }^{*}$ The median difference is significant at the $\mathrm{p}<0.001$ 
Finally, a test was performed to investigate the association between "ability to interpret the value of coefficient of correlation, $r$ " and "ability to interpret the value of slope, $b_{1}$ " among the students. The chi-square test was proceeded, with the met assumption of expected frequency less than 5 in less than $20 \%$ of the cells. A Chi-square test for independence (see Table 9) indicated significant association between "ability to interpret the value of $r$ " and "ability to interpret the value of $b_{1} ", \chi^{2}(4, N=211)=15.563, p=0.004$.It can be seen that, from 41 students who can interpret the value of $r, 20$ of them $(48.8 \%)$ can also interpret the value of $b_{1}$ correctly. Meanwhile, from 39 students who gave a wrong interpretation for $\mathrm{r}, 28$ of them $(71.8 \%)$ gave wrong or no interpretation of $b_{1}$. For those who gave an incomplete interpretation of $r(n=131)$, mostly $(47.3 \%)$ would give wrong or no interpretation of the $b_{1}$. This finding is as expected since the interpretation of the slope $\left(b_{1}\right)$ needs students understanding not only on the concept of the slope, but also on the concept of correlation coefficient.

Table 9.The association between students' ability to interpret the value of $r$ and the value of $b_{1}(N=211)$

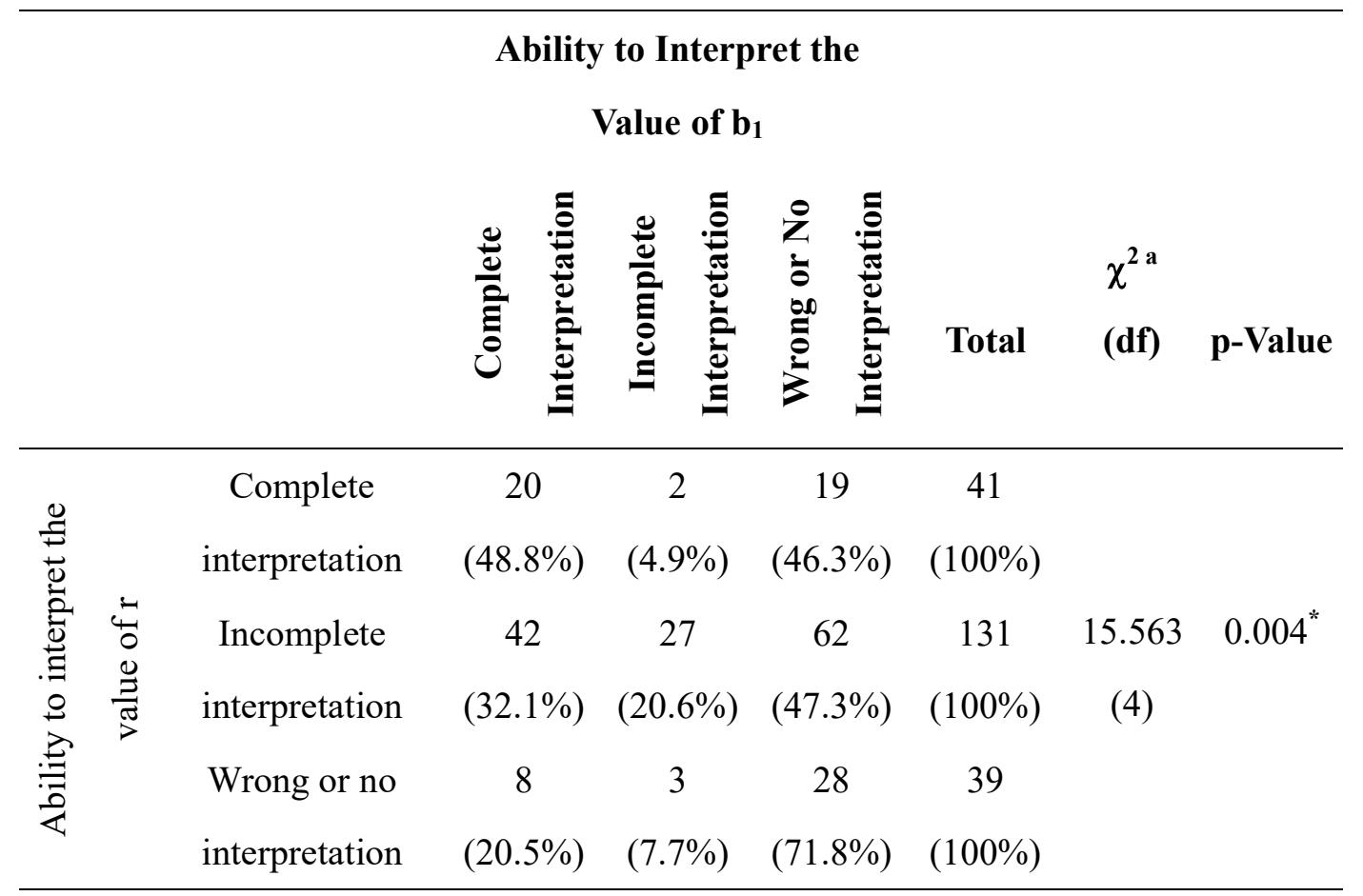

${ }^{\mathrm{a}}$ Chi-square test; ${ }^{*}$ The association is significant at the $\mathrm{p}=0.004$ 


\section{CONCLUSION}

The ability to give complete interpretation of correlation coefficient is quite low among university students. Most of the students missed at least one important term such as "positive", "strong" and "linear", simply stating " $x "$ and " $y$ " without specifically relating the interpretation in the context of the problem, resulting to incomplete interpretation. Students who able to interpret completely also shows a great understanding on the correlation analysis as they managed to get an average score of 9.4 with small variability $(\mathrm{SD}=1.1)$ as compared to those who gave wrong or no interpretation. This might give some indication that for those who were unable to give correct interpretation, they may also have problems in understanding the correlation analysis itself. In contrary with the interpretation of slope, most of the students were unable to give any interpretation or provided incorrect explanation with agreat variability $(\mathrm{SD}=4.6)$, suggesting that they mayalso have difficulties in grasping the regression analysis idea. In this interpretation, students were found to have problems in identifying the effect of independent variable to the dependent variable during the interpretation phase, even though they succeeded to assign $\mathrm{x}$ and $\mathrm{y}$ correctly during the calculating phase. Apart from that, general comments without properly describing the variables involved, as well as failure to convey their understanding as a result of low proficiency in English Language, contributed to the low percentage of complete interpretation by students.

Finally, this study suggests that the ability of students to give comprehensive explanation of correlation coefficient, $\mathrm{r}$ is associated with the ability to give thorough interpretation of slope, $b_{1}$. Therefore, educators need to ensure students understanding on correlation analysis before succeeding on regression analysis. Failure to do so would result on average or poor performance as the students will not only fail to give valid interpretation, but they will also have problems to understand the higher concept involving multiple regression analysis. Last but not least, the findings obtained from this study will shed some lights, especially for statistics educators in improving their teaching practices so as to help their students in gaining a better understanding on interpreting the correlation and regression analysis. 


\section{ACKNOWLEDGEMENTS}

The study is financially funded by the Academic \& Research Assimilation Grant, UniversitiTeknologi MARA, 600-IRMI/DANA 5/3/ARAS (0180/2016). Special thanks are also extended to all those who participated directly and indirectly in this study.

\section{REFERENCES}

[1] Gal I, Ginsbur L. The role of belief and attitudes in learning statistics: Towards an assessment framework.Journal of Statistics Education, 1994,2(2):1-15

[2] BaharunN, Porter A. Use of CAOS test in introductory statistics subject. In 7th International Conference on University Learning and Teaching, 2016, pp. 61-74

[3] McDonald G C. Shaping statistics for success in the 21st century: The needs of industry. The American Statistican, 1999, 53(3):203-207

[4] Watson J. M. Statistical literacy at school: Growth and goals. New Jersey: Routledge, 2011

[5] Gal I.Adults' statistical literacy:Meanings,components, responsibilities. International Statistical Review, 2002, 70(1):1-25

[6] Ong J K, Shahrill M. Investigating students' competence level in secondary school statistics. In International Conference on Social Sciences and Humanities, 2014, pp. 912-922

[7] KellyA E, SloaneF, WhittakerA.Simple approaches to assessing underlying understanding of statistical concepts. In I. Gal, \&J. B. Garfield (Eds.), Theassessment challenge in statistics education. Amsterdam: IOS Press, 1997, pp. 85-90

[8] Cobb G W,Moore D S. Mathematics, statistics, and teaching. The American Mathematical Monthly, 1997, 104(9):801-823

[9] Garfield J. How students learn statistics. International Statistical Review, 1995,63(1):25-34

[10]Batanero C, Godino JD, Vallecillos A, Green D R, Holmes P. Errors and difficulties in understanding elementary statistical concepts. International Journal of Mathematical Education in Science and Technology, 1994, 25(4):527-547

[11]Wild C J, Pfannkuch M, Regan M. Towards more accessible conceptions of statistical inference. Journal of the Royal Statistical Society: Series A (Statistics in Society), 2011, 
174(2):247-295

[12]Gordon S. A theoretical approach to understanding learners of statistics. Journal of Statistics Education, 1995 3(3):1-21

[13]Wiberg M. Teaching statistics in integration with psychology. Journal of Statistics Education,2009, 17(1):1-16

[14]Francis G. An approach to report writing in statistics courses. In IASE Satellite Conference on Statistics Education and the Communication of Statistics, 2005, pp. 1-7

[15] Sawir E. Language difficulties of international students in Australia: The effects of prior learning experience.International Education Journal, 2005, 6(5):567-580

[16]Montgomery D. C.,PeckE. A.,Vining G. G. Introduction to linear regression analysis. New Jersey: John Wiley and Sons, 2015

\section{How to cite this article:}

Ismail N. R. P, Razak F. A, Baharun N, and Deraman N. A. Assessing Students' Abilities In Interpreting The Correlation And Regression Analysis. J. Fundam. Appl. Sci., 2017, 9(9S), 644-661. 